\title{
International Geomagnetic Reference Field—the eighth generation
}

\author{
Mioara Mandea ${ }^{1}$ and Susan Macmillan ${ }^{2}$ \\ ${ }^{1}$ Institut de Physique du Globe de Paris, B.P. 89, 4 Place Jussieu, 75252 Paris cedex 5, France \\ ${ }^{2}$ British Geological Survey, Murchison House, West Mains Road, Edinburgh, EH9 3LA, U.K.
}

(Received February 14, 2000; Revised May 15, 2000; Accepted May 18, 2000)

\begin{abstract}
The eighth generation of the International Geomagnetic Reference Field (IGRF) was adopted in 1999 by the International Association of Geomagnetism and Aeronomy (IAGA) Division V, Working Group 8. This differs from the previous generation by the addition of the IGRF 2000 which comprises a main-field model for the epoch 2000.0 and a predictive secular-variation model for 2000.0-2005.0. This paper lists the IGRF coefficients and includes contour maps computed using IGRF 2000.
\end{abstract}

\section{Introduction}

A group of geomagnetic field modellers associated with the International Association of Geomagnetism and Aeronomy (IAGA) Division V, Working Group 8, periodically examines various geomagnetic field representations from which the Earth's main field and its secular variation can be computed. They produce a set of coefficients to represent the main field at a particular epoch, usually every five years, and name it the International Geomagnetic Reference Field (IGRF). Also, if a previous IGRF is re-derived using new data not available at the time of its production and agreed upon when it is clear no additional data are likely to emerge, it is called a Definitive Geomagnetic Reference Field (DGRF). Note that, when referring to these models, the designation "IGRF" refers to all available models, viewed collectively. If a particular model is intended, the reference must be specific, i.e. IGRF 2000 or DGRF 2000, rather than simply IGRF or DGRF.

\section{Field Modelling}

The IGRF is a series of mathematical models describing the Earth's main field and its secular variation. The main field is the negative spatial gradient of a scalar potential $V_{i}(r, \theta, \phi, t)$ which satisfies Laplace's equation. Each model comprises a set of spherical harmonics, each of which is a solution to Laplace's equation:

$$
\begin{array}{r}
V_{i}(r, \theta, \phi, t)=a \sum_{n=1}^{N} \sum_{m=0}^{n}\left(\frac{a}{r}\right)^{n+1}\left(g_{n}^{m}(t) \cos m \phi\right. \\
\left.+h_{n}^{m}(t) \sin m \phi\right) P_{n}^{m}(\cos \theta)
\end{array}
$$

where $a=6371.2 \mathrm{~km}$ is the mean radius of the Earth, $r$ denotes the radial distance from the centre of the Earth, $\theta$ denotes the geocentric colatitude, $\phi$ denotes the east longitude, $t$ is the time, $P_{n}^{m}(\cos \theta)$ are the Schmidt-normalized associated Legendre functions of degree $n$ and order $m$, and $g_{n}^{m}(t)$

Copy right $($ C The Society of Geomagnetism and Earth, Planetary and Space Sciences (SGEPSS); The Seismological Society of Japan; The Volcanological Society of Japan; The Geodetic Society of Japan; The Japanese Society for Planetary Sciences. and $h_{n}^{m}(t)$ are the corresponding Gauss coefficients. When converting between geocentric and geodetic coordinates, the use of the IAU ellipsoid (International Astronomical Union, 1966) is recommended (equatorial radius of $6378.160 \mathrm{~km}$ and flattening 1/298.25). The maximum spherical harmonic degree of the expansion is $N$.

The temporal dependence of the Gauss coefficients is:

$$
\begin{aligned}
& g_{n}^{m}(t)=g_{n}^{m}\left(T_{0}\right)+\dot{g}_{n}^{m}\left(t-T_{0}\right) \\
& h_{n}^{m}(t)=h_{n}^{m}\left(T_{0}\right)+\dot{h_{n}^{m}}\left(t-T_{0}\right)
\end{aligned}
$$

where $g_{n}^{m}$ and $h_{n}^{m}$ represent the Gauss coefficients for the secular variation, i.e. the first temporal derivative of $g_{n}^{m}(t)$ and $h_{n}^{m}(t), T_{0}$ is the epoch of the main-field model, and $t$ is the date for which model values are required $\left(T_{0} \leq t \leq T_{0}+5\right)$.

The IGRF models for the main field are truncated at $N=$ 10 (120 coefficients) which represents a compromise adopted to produce well-determined main-field models while avoiding most of the contamination resulting from crustal sources. The coefficients of the main field are rounded to the nearest nanotesla (nT) to reflect the limit of the resolution of the available data. Coefficients for dates between the 5-year epochs are obtained by linear interpolation between the corresponding main-field coefficients for the neighbouring epochs. The IGRF predictive model for the secular variation is truncated at $N=8$ (80 coefficients). In this case the coefficients are rounded to the nearest $0.1 \mathrm{nT} / \mathrm{year}$, to reduce the effect of accumulated rounding error.

\section{Candidate Models for the eighth Generation IGRF}

The call for candidate models put out by IAGA Working Group V-8 requested only an IGRF model for 2000 (main field and secular variation). A DGRF model for 1995.0 was not requested as it was felt that there were not sufficient data available on which to base such a model. Three candidate models were submitted by the British Geological Survey/US Geological Survey (Macmillan and Quinn, 2000), the Institut de Physique du Globe de Paris (Langlais and Mandea, 2000), the Institute of Terrestrial Magnetism, Ionospheric 
Table 1. Spherical harmonic (Gauss) coefficients of the IGRF 2000 and SV 2000-2005.

\begin{tabular}{|c|c|c|c|c|c|c|c|c|c|}
\hline$g / h$ & $n$ & $m$ & $\begin{array}{l}\text { IGRF } 2000 \\
\quad(\mathrm{nT})\end{array}$ & $\begin{array}{c}\text { SV 2000-2005 } \\
\text { (nT/year) }\end{array}$ & $g / h$ & $n$ & $m$ & $\begin{array}{c}\text { IGRF } 2000 \\
\text { (nT) }\end{array}$ & $\begin{array}{c}\text { SV 2000-2005 } \\
\text { (nT/year) }\end{array}$ \\
\hline$g$ & 1 & 0 & -29615 & 14.6 & $g$ & 6 & 6 & -91 & 1.2 \\
\hline$g$ & 1 & 1 & -1728 & 10.7 & $h$ & 6 & 6 & 44 & 0.9 \\
\hline$h$ & 1 & 1 & 5186 & -22.5 & $g$ & 7 & 0 & 79 & -0.4 \\
\hline$g$ & 2 & 0 & -2267 & -12.4 & $g$ & 7 & 1 & -74 & -0.4 \\
\hline$g$ & 2 & 1 & 3072 & 1.1 & $h$ & 7 & 1 & -65 & 1.1 \\
\hline$h$ & 2 & 1 & -2478 & -20.6 & $g$ & 7 & 2 & 0 & -0.3 \\
\hline$g$ & 2 & 2 & 1672 & -1.1 & $h$ & 7 & 2 & -24 & 0.0 \\
\hline$h$ & 2 & 2 & -458 & -9.6 & $g$ & 7 & 3 & 33 & 1.1 \\
\hline$g$ & 3 & 0 & 1341 & 0.7 & $h$ & 7 & 3 & 6 & 0.3 \\
\hline$g$ & 3 & 1 & -2290 & -5.4 & $g$ & 7 & 4 & 9 & 1.1 \\
\hline$h$ & 3 & 1 & -227 & 6.0 & $h$ & 7 & 4 & 24 & -0.1 \\
\hline$g$ & 3 & 2 & 1253 & 0.9 & $g$ & 7 & 5 & 7 & -0.2 \\
\hline$h$ & 3 & 2 & 296 & -0.1 & $h$ & 7 & 5 & 15 & -0.6 \\
\hline$g$ & 3 & 3 & 715 & -7.7 & $g$ & 7 & 6 & 8 & 0.6 \\
\hline$h$ & 3 & 3 & -492 & -14.2 & $h$ & 7 & 6 & -25 & -0.7 \\
\hline$g$ & 4 & 0 & 935 & -1.3 & $g$ & 7 & 7 & -2 & -0.9 \\
\hline$g$ & 4 & 1 & 787 & 1.6 & $h$ & 7 & 7 & -6 & 0.2 \\
\hline$h$ & 4 & 1 & 272 & 2.1 & $g$ & 8 & 0 & 25 & -0.3 \\
\hline$g$ & 4 & 2 & 251 & -7.3 & $g$ & 8 & 1 & 6 & 0.2 \\
\hline$h$ & 4 & 2 & -232 & 1.3 & $h$ & 8 & 1 & 12 & 0.1 \\
\hline$g$ & 4 & 3 & -405 & 2.9 & $g$ & 8 & 2 & -9 & -0.3 \\
\hline$h$ & 4 & 3 & 119 & 5.0 & $h$ & 8 & 2 & -22 & 0.0 \\
\hline$g$ & 4 & 4 & 110 & -3.2 & $g$ & 8 & 3 & -8 & 0.4 \\
\hline$h$ & 4 & 4 & -304 & 0.3 & $h$ & 8 & 3 & 8 & 0.0 \\
\hline$g$ & 5 & 0 & -217 & 0.0 & $g$ & 8 & 4 & -17 & -1.0 \\
\hline$g$ & 5 & 1 & 351 & -0.7 & $h$ & 8 & 4 & -21 & 0.3 \\
\hline$h$ & 5 & 1 & 44 & -0.1 & $g$ & 8 & 5 & 9 & 0.3 \\
\hline$g$ & 5 & 2 & 222 & -2.1 & $h$ & 8 & 5 & 15 & 0.6 \\
\hline$h$ & 5 & 2 & 172 & 0.6 & $g$ & 8 & 6 & 7 & -0.5 \\
\hline$g$ & 5 & 3 & -131 & -2.8 & $h$ & 8 & 6 & 9 & -0.4 \\
\hline$h$ & 5 & 3 & -134 & 1.7 & $g$ & 8 & 7 & -8 & -0.7 \\
\hline$g$ & 5 & 4 & -169 & -0.8 & $h$ & 8 & 7 & -16 & 0.3 \\
\hline$h$ & 5 & 4 & -40 & 1.9 & $g$ & 8 & 8 & -7 & -0.4 \\
\hline$g$ & 5 & 5 & -12 & 2.5 & $h$ & 8 & 8 & -3 & 0.7 \\
\hline$h$ & 5 & 5 & 107 & 0.1 & $g$ & 9 & 0 & 5 & 0.0 \\
\hline$g$ & 6 & 0 & 72 & 1.0 & $g$ & 9 & 1 & 9 & 0.0 \\
\hline$g$ & 6 & 1 & 68 & -0.4 & $h$ & 9 & 1 & -20 & 0.0 \\
\hline$h$ & 6 & 1 & -17 & -0.2 & $g$ & 9 & 2 & 3 & 0.0 \\
\hline$g$ & 6 & 2 & 74 & 0.9 & $h$ & 9 & 2 & 13 & 0.0 \\
\hline$h$ & 6 & 2 & 64 & -1.4 & $g$ & 9 & 3 & -8 & 0.0 \\
\hline$g$ & 6 & 3 & -161 & 2.0 & $h$ & 9 & 3 & 12 & 0.0 \\
\hline$h$ & 6 & 3 & 65 & 0.0 & $g$ & 9 & 4 & 6 & 0.0 \\
\hline$g$ & 6 & 4 & -5 & -0.6 & $h$ & 9 & 4 & -6 & 0.0 \\
\hline$h$ & 6 & 4 & -61 & -0.8 & $g$ & 9 & 5 & -9 & 0.0 \\
\hline$g$ & 6 & 5 & 17 & -0.3 & $h$ & 9 & 5 & -8 & 0.0 \\
\hline$h$ & 6 & 5 & 1 & 0.0 & $g$ & 9 & 6 & -2 & 0.0 \\
\hline
\end{tabular}


Table 1. (continued).

\begin{tabular}{|c|c|c|c|c|}
\hline$g / h$ & $n$ & $m$ & $\begin{array}{l}\text { IGRF } 2000 \\
\text { (nT) }\end{array}$ & $\begin{array}{c}\text { SV 2000-2005 } \\
\text { (nT/year) }\end{array}$ \\
\hline$h$ & 9 & 6 & 9 & 0.0 \\
\hline$g$ & 9 & 7 & 9 & 0.0 \\
\hline$h$ & 9 & 7 & 4 & 0.0 \\
\hline$g$ & 9 & 8 & -4 & 0.0 \\
\hline$h$ & 9 & 8 & -8 & 0.0 \\
\hline$g$ & 9 & 9 & -8 & 0.0 \\
\hline$h$ & 9 & 9 & 5 & 0.0 \\
\hline$g$ & 10 & 0 & -2 & 0.0 \\
\hline$g$ & 10 & 1 & -6 & 0.0 \\
\hline$h$ & 10 & 1 & 1 & 0.0 \\
\hline$g$ & 10 & 2 & 2 & 0.0 \\
\hline$h$ & 10 & 2 & 0 & 0.0 \\
\hline$g$ & 10 & 3 & -3 & 0.0 \\
\hline$h$ & 10 & 3 & 4 & 0.0 \\
\hline$g$ & 10 & 4 & 0 & 0.0 \\
\hline$h$ & 10 & 4 & 5 & 0.0 \\
\hline$g$ & 10 & 5 & 4 & 0.0 \\
\hline$h$ & 10 & 5 & -6 & 0.0 \\
\hline$g$ & 10 & 6 & 1 & 0.0 \\
\hline$h$ & 10 & 6 & -1 & 0.0 \\
\hline$g$ & 10 & 7 & 2 & 0.0 \\
\hline$h$ & 10 & 7 & -3 & 0.0 \\
\hline$g$ & 10 & 8 & 4 & 0.0 \\
\hline$h$ & 10 & 8 & 0 & 0.0 \\
\hline$g$ & 10 & 9 & 0 & 0.0 \\
\hline$h$ & 10 & 9 & -2 & 0.0 \\
\hline$g$ & 10 & 10 & -1 & 0.0 \\
\hline$h$ & 10 & 10 & -8 & 0.0 \\
\hline
\end{tabular}

and Radio Wave Propagation, Moscow (Golovkov et al., 2000). In addition, the Chairman, C. Barton, suggested the 2000.0 value of the seventh generation IGRF. As none of these four main-field models was deemed sufficiently accurate for an IGRF model (Macmillan, 2000; Mandea and Langlais, 2000) and because of the successful launch and operation of the Ørsted satellite after the submission deadline, it was decided at the XXII General Assembly of the International Union of Geodesy and Geophysics held in Birmingham (UK) in July 1999 to set up a Task Force to produce and evaluate a new IGRF main-field candidate model for 2000.0 based on Ørsted data. The operation of the Task Force is summarised by Lowes (2000), details of the derivation of this model are given in Olsen and Sabaka (2000) and of its evaluation by Lowes et al. (2000). For the secular-variation model for 2000.0-2005.0 the three new candidate models were each given equal weight in the final model as there was insufficient evidence to recommend one model over another.

For more details on main-field modelling the reader is referred to Chapman and Bartels (1940), Langel (1987) and Merrill et al. (1996). A review of the history of the IGRF and how well the coefficients are determined is given by Barton (1997).

\section{IGRF Data Products}

General Information about the IGRF is given at http: // www. ngdc.noaa.gov/IAGA/wg8/igrf2000.html.

The coefficients of the eighth generation IGRF are listed in Table 1, and are available at: http: //www.ngdc noaa . gov/IAGA/wg8/table1.txt.

Computer programs for synthesizing the field components are available from: http://www.ngdc.noaa.gov/ seg/potfld/magmodel . shtml.

On-line computation of the field components for a specific location and time is available at (last one for 2000.0 only): http://www.ngdc.noaa.gov/cgi-bin/seg/ gmag/fldsnthl.pl, http://www.nmh.ac.uk/gifs/ igrf_form.html, http://swdcdb.kugi.kyoto-u. ac.jp:80/igrf/point.

This information can also be obtained from the World Data Centres listed in the Appendix.

Figures 1 to 7 show contour maps of the IGRF2000 for all seven field elements. The upper map in each figure shows the main-field element and the lower map the secular (annual) change. For further information about the IGRF models contact IAGA Working Group V-8 (Chair: Mioara Mandea, Institut de Physique du Globe de Paris, 4 Place Jussieu, 75252 Paris, France. Fax: 33238339 504, email: mioara@ipgp.jussieu.fr).

\section{Appendix. World Data Centres}

World Data Center for Solid Earth Geophysics, Boulder National Geophysical Data Center 325 Broadway, Boulder CO 80303, USA

e-mail: info@ngdc.noaa.gov

http://www.ngdc.noaa.gov/seg/potfld/

geomag.shtml

Fax: +1 3034976513

World Data Centre for Geomagnetism, Edinburgh British Geological Survey, Murchison House West Mains Road, Edinburgh EH9 3LA, UK e-mail: S.Macmillan@bgs.ac.uk http://www.nmh.ac.uk/gifs/igrf.html Fax: +441316684368

World Data Center for Geomagnetism, Kyoto Graduate School of Science, Kyoto University Kyoto 606-8502, JAPAN e-mail: iyemori@kugi.kyoto-u.ac.jp http://swdcdb.kugi.kyoto-u.ac.jp/igrf/ Fax: +81757227884 
Declination (degrees) at 2000.0.

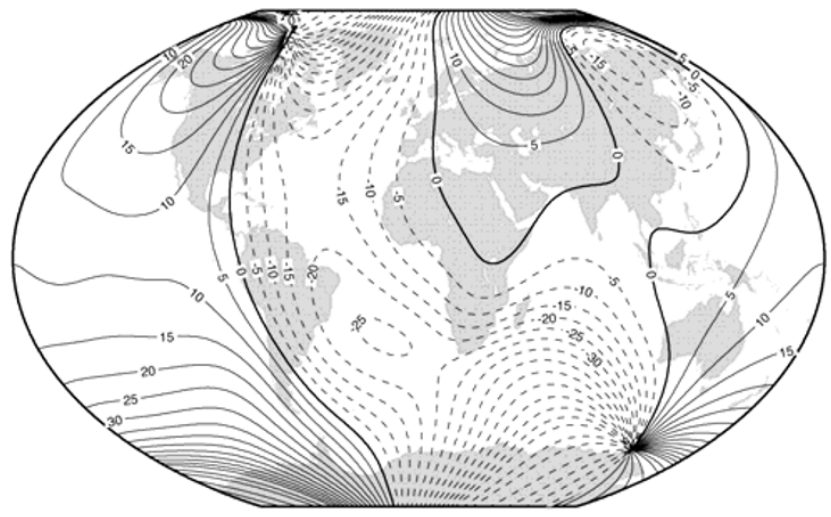

Secular variation of declination $(\mathrm{min} / \mathrm{yr})$ for 2000.0-2005.0.

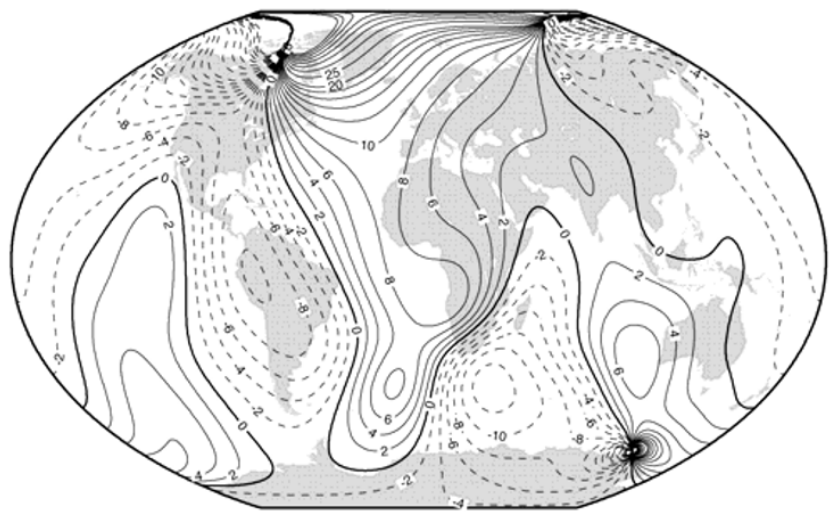

Fig. 1. Contour maps of the IGRF 2000 for D component (Winkel's Tripel projection).

Horizontal intensity (nT) at 2000.0.

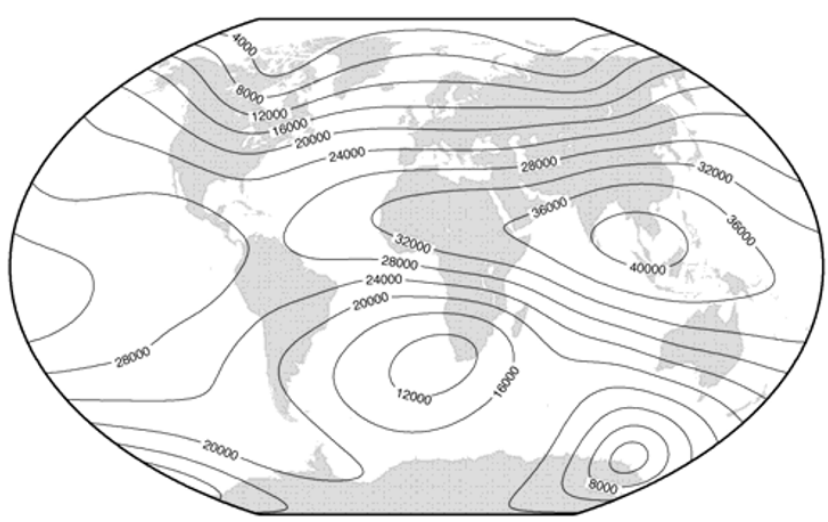

Secular variation of horizontal intensity (nT/yr) for 2000.0-2005.0.

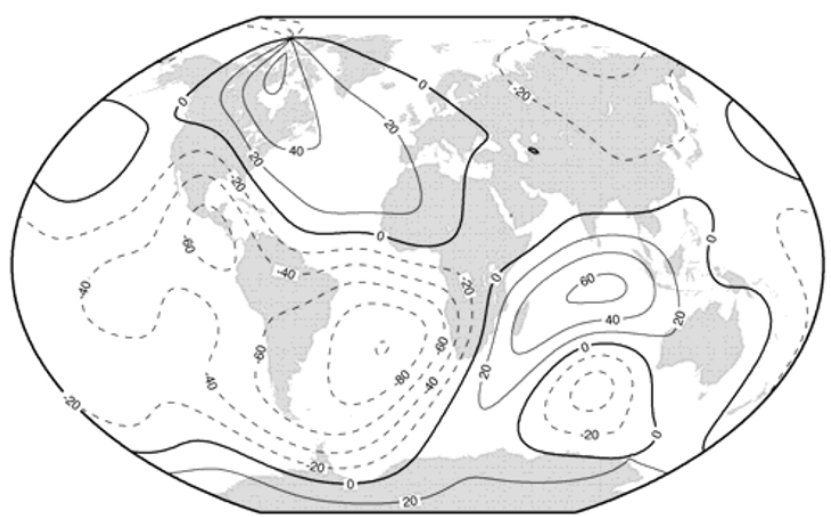

Fig. 2. Contour maps of the IGRF 2000 for $H$ component (Winkel's Tripel projection). Note that the apparent singularity in the northern polar region is an artifact of the plotting routine.

Vertical component (nT) at 2000.0.

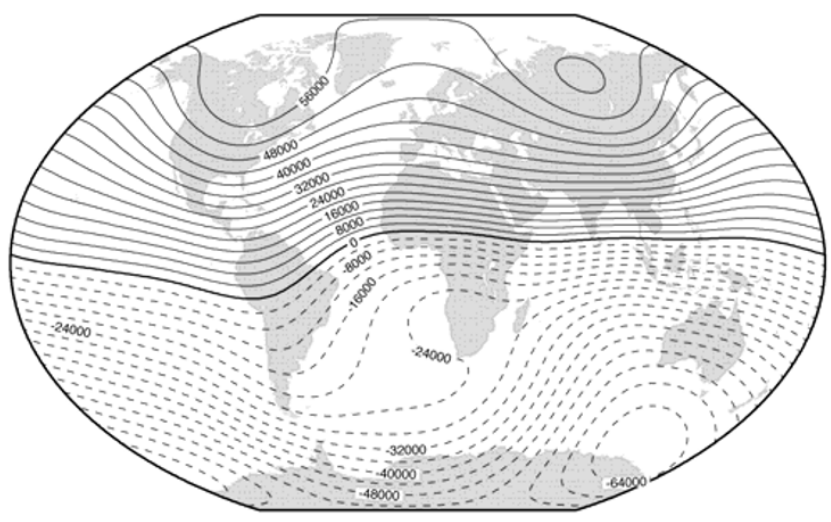

Secular variation of vertical component (nT/yr) for 2000.0-2005.0.

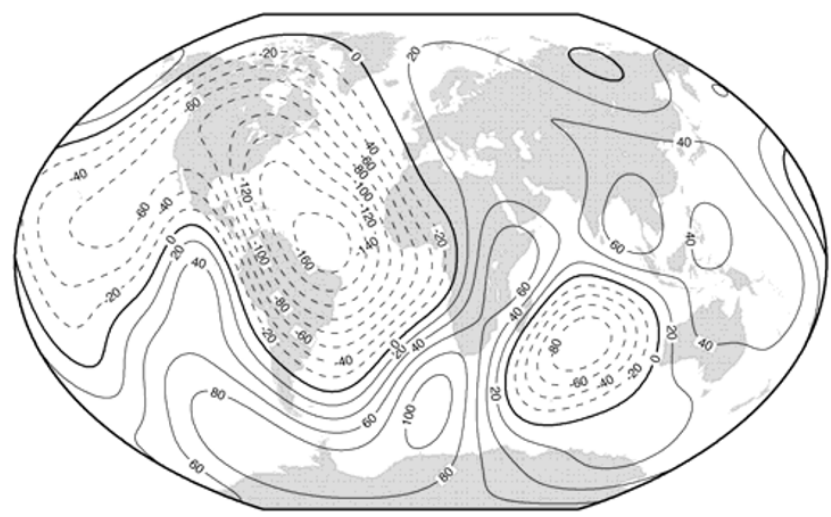

Fig. 3. Contour maps of the IGRF 2000 for $Z$ component (Winkel's Tripel projection). 


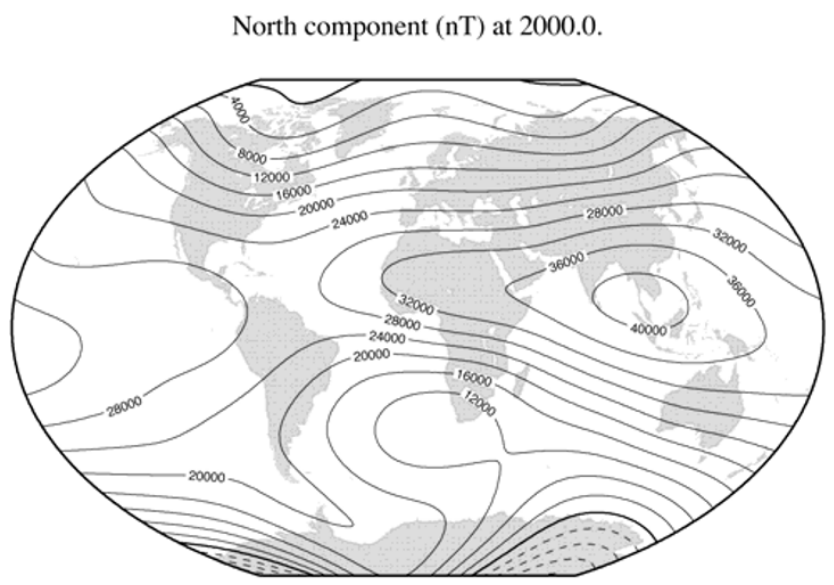

Fig. 4. Contour maps of the IGRF 2000 for $X$ component (Winkel's Tripel projection).
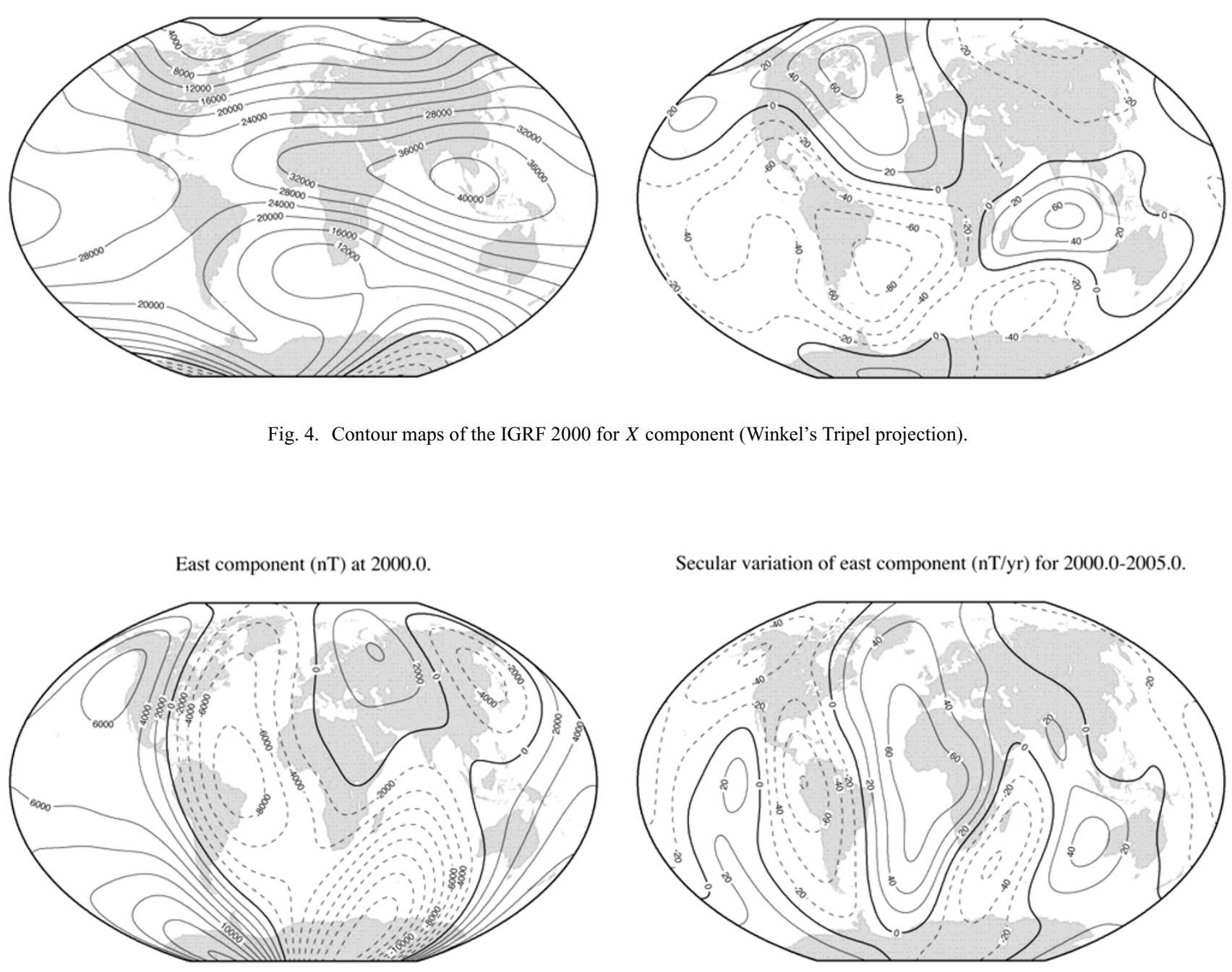

Fig. 5. Contour maps of the IGRF 2000 for $Y$ component (Winkel's Tripel projection).

Inclination (degrees) at 2000.0.

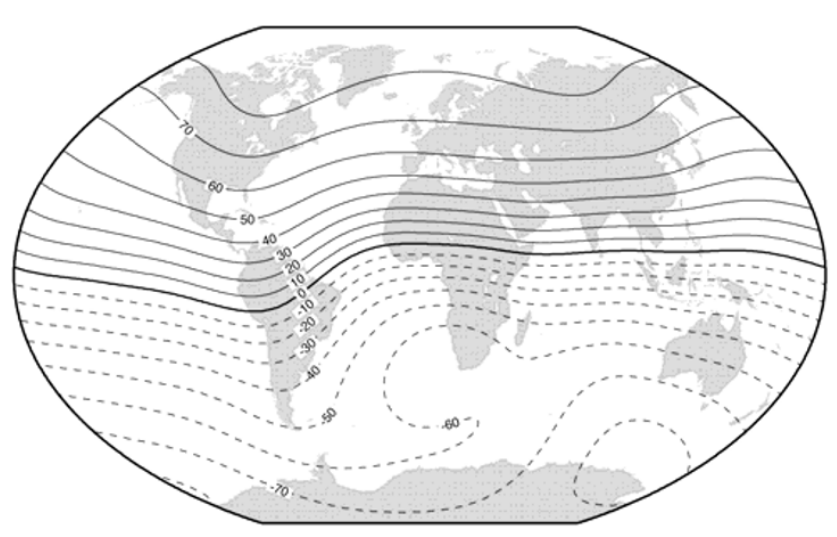

Secular variation of east component (nT/yr) for 2000.0-2005.0.

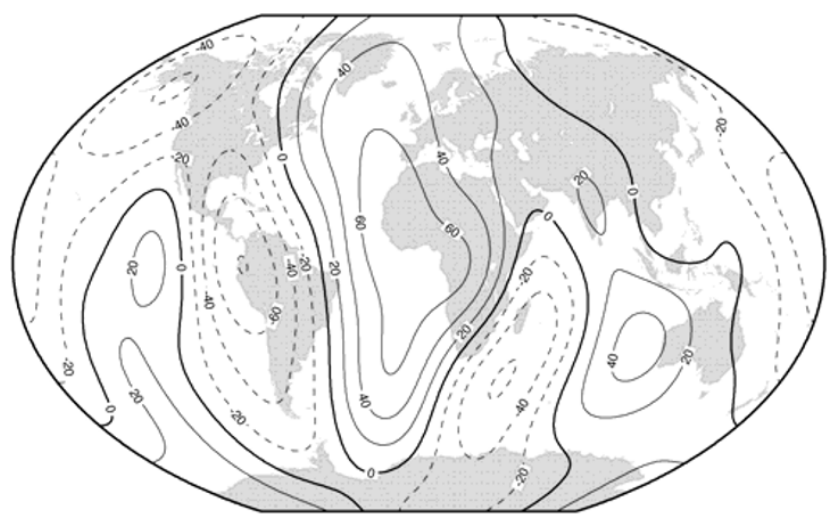

Fig. 6. Contour maps of the IGRF 2000 for $I$ component (Winkel's Tripel projection). 
Total intensity $(\mathrm{nT})$ at 2000.0 .

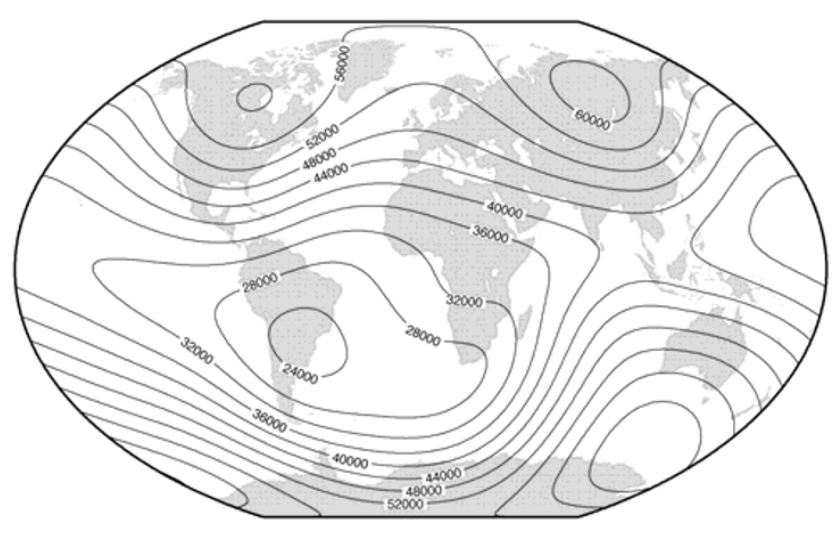

Secular variation of total intensity (nT/yr) for 2000.0-2005.0.

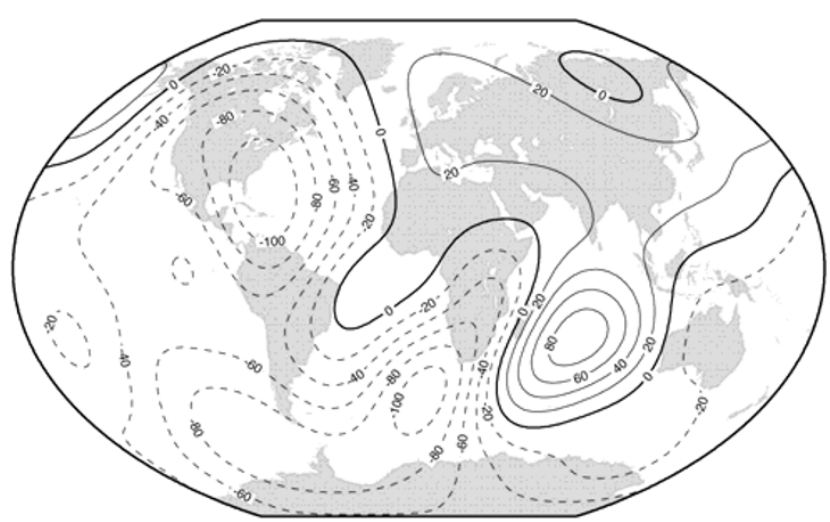

Fig. 7. Contour maps of the IGRF 2000 for $F$ component (Winkel's Tripel projection).

Acknowledgments. We would like to thank the Ørsted team, the staff of magnetic observatories and survey organisations worldwide for providing data on which the IGRF depends and the World Data Centres for data services. We also thank Stuart Malin and Volodya Papitashvili for comments, and the associate editor Frank Lowes for useful discussions. All maps have been plotted using the GMT software (Wessel and Smith, 1991). This paper is published with the permission of the Director, British Geological Survey (Natural Environment Research Council). This is IPGP contribution 1703.

\section{References}

Barton, C. E., International Geomagnetic Reference Field: the seventh generation, J. Geomag. Geoelectr., 49, 123-148, 1997.

Chapman, S. and J. Bartels, Geomagnetism, 2 vols., pp. 1049, Oxford University Press, London, 1940.

Golovkov, V. P., T. N. Bondar, and I. A. Burdelnaya, Spatial-temporal modeling of the geomagnetic field for 1980-2000 period and a candidate IGRF secular-variation model for 2000-2005, Earth Planets Space, 52, this issue, $1125-1135,2000$.

International Astronomical Union, Proc. 12th General Assembly, Hamburg, 12B, 594-595, 1966.

Langel, R. A., Main field, in Geomagnetism, edited by J. A. Jacobs, pp. 249 512, vol. I, Academic Press, London, 1987.

Langlais, B. and M. Mandea, An IGRF candidate main geomagnetic field model for epoch 2000 and a secular variation model for 2000-2005, Earth
Planets Space, 52, this issue, 1137-1148, 2000.

Lowes, F. J., The working of the IGRF 2000 Task Force, Earth Planets Space, 52, this issue, 1171-1174, 2000.

Lowes, F. J., T. Bondar, V. P. Golovkov, B. Langlais, S. Macmillan, and M. Mandea, Evaluation of the candidate Main Field model for IGRF 2000 derived from preliminary Ørsted data, Earth Planets Space, 52, this issue, 1183-1186, 2000

Macmillan, S., An evaluation of candidate geomagnetic field models for IGRF 2000, Earth Planets Space, 52, this issue, 1163-1165, 2000.

Macmillan, S. and J. M. Quinn, The 2000 revision of the joint UK/US geomagnetic field models and an IGRF 2000 candidate model, Earth Planets Space, 52, this issue, 1149-1162, 2000.

Mandea, M. and B. Langlais, Use of Ørsted scalar data in evaluating the pre-Ørsted main field candidate models for the IGRF 2000, Earth Planets Space, 52, this issue, 1167-1170, 2000.

Merrill, R., M. W. McElhinny, and P. L. McFadden, The magnetic field of the Earth, Paleomagnetism, the core, and the deep mantle, $531 \mathrm{pp}$., Academic Press, San Diego, 1996.

Olsen, N., T. J. Sabaka, and L. Tøffner-Clausen, Determination of the IGRF 2000 model, Earth Planets Space, 52, this issue, 1175-1182, 2000.

Wessel, P. and W. H. F. Smith, Free software helps map and display data, EOS Trans. Am. Geophys. Union, 72, 441-448, 1991.

M. Mandea (e-mail: mioara@ipgp.jussieu.fr) and S. Macmillan (e-mail: S.Macmillan@bgs.ac.uk) 